Research Paper

\title{
Unique Responses of Hepatocellular Carcinoma and Cholangiocarcinoma Cell Lines toward Cantharidin and Norcantharidin
}

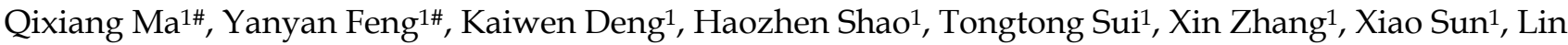 \\ Jin $^{1}$, Zhitao $\mathrm{Ma}^{1}$, Guangbin Luo ${ }^{1,2}$ \\ 1. School of Life Sciences, Centre For Translational Oncology, Beijing University of Chinese Medicine, 11 Beisanhuandong Road, Chaoyang District, Beijing \\ 100029, People's Republic of China. \\ 2. Department of Genetics and Genome Sciences, Case Comprehensive Cancer Center, Case Western Reserve University, Cleveland, OH 44106, USA \\ \# These two authors contributed equally to this work.
}

$\triangle$ Corresponding author: Guangbin Luo, Professor, School of Life Sciences, Centre For Translational Oncology, Beijing University of Chinese Medicine, 11 Beisanhuandong Road, Chaoyang District, Beijing 100029, People's Republic of China. Email: guangbin.luo@case.edu; Telephone: 1-(216)-368-4883 Fax: 1-(216)-368-3432

(C) Ivyspring International Publisher. This is an open access article distributed under the terms of the Creative Commons Attribution (CC BY-NC) license (https://creativecommons.org/licenses/by-nc/4.0/). See http://ivyspring.com/terms for full terms and conditions.

Received: 2018.02.08; Accepted: 2018.03.26; Published: 2018.05.25

\begin{abstract}
The present study aimed to investigate whether cell lines from human gastric and liver cancers respond differently toward cantharidin (CTD) and norcantharidin (NCTD) than other types of cancer cells. We first established the half maximal inhibitory concentrations (IC50s) of CTD for a large panel of cancer cell lines representing the 12 major types of human cancers and the mode of cell death induced by the two compounds. We next compared the growth inhibitory effects as well as the corresponding modes of action of CTD and NCTD. The IncuCyte ZOOM system was used as a semi-high throughput means to define IC50s and $90 \%$ inhibitory doses (IC90s) as a reference for the maximal tolerable doses (MTDs) for the two compounds in 72 cancer cell lines. Classical clonogenic survival assay was used to assess the anti-proliferative effect of CTD on selected cell lines of interest. In addition, DNA content-based flow was used to interrogate the modes of cell death following CTD or NCTD exposure. The results of these experiments led to several findings. 1). Cell lines representing hepatocellular carcinomas (HCCs) and cholangiocarcinomas (CCs) were among the most sensitive toward CTD, consistent with the previous clinical study of this compound and its source of origin, Mylabris. 2). Among the individual cell lines of a given cancer types, the sensitivity trends for CTD and NCTD did not exhibit a good correlation. 3) CTD and NCTD caused distinctive cytotoxic effects on HepG2 cells. Specifically, while a cytostatic effect is the primary cause of growth inhibition of CTD, cytotoxic effect is the main contributing factor for the growth inhibition of NTCD. These results indicate that liver cancer cell lines are among the most sensitive to CTD and that CTD and NCTD exhibit their effects through distinct mechanisms.
\end{abstract}

Key words: Hepatocellular carcinomas; Cholangiocarcinomas; NCI60; Mylabris (Mylabris phalerata Pall. or Mylabris cichorii Linn.); Cantharidin; Norcantharidin; Half maximal inhibitory concentrations (IC50s); Maximal tolerable dose (MTD).

\section{Introduction}

Liver cancers represent one of the major types of cancers worldwide. In particular, hepatocellular carcinomas (HCCs) and Cholangiocarcinomas (CCs) together account for the majority of the cancer incidents in the liver. Sorafenib and Regorafenib are currently the only drugs approved by the US FDA to treat HCCs ${ }^{[1,2]}$, though the effectiveness of these drug is limited ${ }^{[3]}$. No drugs have been approved to treat CCs. Thus, effective drugs for HCC and CC are still in urgent need.

Historically, Mylabris has been reported to be effective for treating liver cancers and gastro- 
esophageal cancers in China ${ }^{[3]}$. Moreover, modern clinical studies have showed that cantharidin (CTD), the presumed active antitumor compound of Mylabris, was effective in treating HCCs and gastro-esophageal cancer ${ }^{[4]}$, despite the fact that both Mylabris and CTD are potent poison ${ }^{[4]}$. Remarkably, it is generally accepted that the main in vivo anti-tumor target of CTD is protein phosphatases 2A (PP2A) ${ }^{[9}$, 10-13], suggesting that PP2A inhibition may be the underlying anti-tumor mechanism for CTD. However, as PP2A is generally considered a tumor suppressor, inhibiting PP2A should promote, not suppress tumor growth. Yet, it is also clear that PP2A is involved in many signaling pathways and could act in distinct fashions. A PP2A-inhibiting compound could potentially bind more favorably to a certain subtype or subtypes of PP2A, and/or exhibits organ/tissue specific accumulation, therefore exerting a growth inhibitory effect on specific types of tumors. Thus, inhibiting PP2A by CTD and other PP2A specific drugs remains a possible strategy for achieving antitumor therapeutic benefit. It follows that CTD could be uniquely effective for a subset of liver cancers and/or gastro-esophageal cancers. Accordingly, therapies based on CTD and/or its functional derivatives remain a promising strategy when effective treatments for liver cancers is lacking.

Meanwhile, given the extraordinary toxicity of CTD[4,5], a major effort has been focused on developing CTD derivatives with a better toxicity profile. This has led to the development of Norcantharidin (NCTD), the demethylated derivative of CTD ${ }^{[6-8]}$. It was originally assumed that CTD and NCTD have similar modes of action and hence exert their anti-cancer activities through shared mechanism(s), i.e. by inhibiting PP2A[14-17]. However, in order to develop these compounds as anticancer treatments for liver cancers, it is important to empirically determine the modes of action of CTD and NCTD.

In this study, we set out to define the IC50s of CTD and NCTD in a large panel of human cancer cell lines representing twelve different types of human cancers to determine the susceptibility of specific cell lines and/or cancer types to the growth inhibitory effect of CTD, and to determine whether CTD and NCTD affect cells similarly or in distinct fashions.

\section{Materials and methods}

\section{Cell lines and culture condition}

The human cancer cell lines NCI60 were from ATCC. The gastric cancer cell lines and the hepatocellular carcinoma cancer cell lines were gifts from Dr. Youyong Lu of Beijing Institute for Cancer
Research (Beijing, China) and Dr. Guangbiao Zhou of Institute of Zoology, Chinese Academy of Sciences (Beijing, China). The cholangiocarcinoma cell lines QBC939, HCCC9810 and RBE were from the Procell Life Science \&Technology (Wuhan, China). All cells were maintained in RPMI-1640 medium (Gibco, United States) supplemented with $10 \%$ fetal bovine serum (Gibco, United States) and incubated at $37^{\circ} \mathrm{C}$ in a humidified atmosphere of $5 \% \mathrm{CO}_{2}$ in air.

\section{Cell growth inhibition assay}

IncuCyte ZOOM Live-Cell Imaging system (Essen Bioscience, United States) was used to monitor the kinetics of cell growth inhibition by CTD or NCTD (MANSTINE, China) in 72 human cancer cell lines. Cells were seeded at 3,000 cells/well in 96-well plates and treated with increasing concentrations of CTD $(0-32 \mu \mathrm{M})$ or NCTD $(0-160 \mu \mathrm{M})$ in RPMI1640 with $10 \%$ FBS. The plate was scanned and phase-contrast images were acquired in real time every 4 hours from 0 to 72 hours post treatment. Ratios of cell growth confluence in CTD or NCTD treated cells compare to vehicle were plotted in Microsoft Excel. The growth curves for individual cancer lines were generated using GraphPad Prism v.5 software. IC50 and IC90 values were calculated by logistic regression with Probit Analysis using SPSS program.

\section{Clonogenic survival assay}

Cells were trypsinized into single-cell suspension and seeded at 200 cells/well in 6-well plates and treated with increasing concentrations of CTD $(0-5 \mu \mathrm{M})$ and incubated for $10 \mathrm{~d}$ to allow for colony growth. Then, the cells were fixed and stained with crystal violet, and colonies having at least 50 cells were counted under a microscope.

\section{DNA content-based flow assay}

Flow cytometric analysis was performed to identify DNA content and to measure the percentage of SubG1 cells after PI staining in PBS as described. Briefly, CTD or NCTD treated cells were suspended and fixed at $75 \%$ alcohol overnight. Then, the cells were stained with $50 \mu \mathrm{M}$ propidium iodide and incubated for $15 \mathrm{~min}$ at room temperature and analyzed by a flow cytometer (BD, USA). The percentage of apoptotic cells with a DNA content of less than that of G1 cells was estimated with Listmode software. In addition, cell cycle analysis was performed simultaneously with Multicycle software.

\section{Statistical analysis}

Data are presented as $\pm \mathrm{SD}$, and statistical analyses were performed using one-way ANOVA for multiple group comparisons. $P<0.05$ was considered 
statistically significant. Mean values and SD were calculated for experiments performed in triplicate.

Table 1. CTD IC50 for $\mathrm{NCl} 60$ cell lines

\begin{tabular}{|c|c|c|c|}
\hline $\begin{array}{l}\text { Human cancer cell } \\
\text { line }\end{array}$ & $\begin{array}{l}\text { IC50 }(\mu \mathrm{M}) \text { of } \\
\text { CTD }\end{array}$ & $\begin{array}{l}\text { Human cancer cell } \\
\text { line }\end{array}$ & $\begin{array}{l}\text { IC50 }(\mu \mathrm{M}) \text { of } \\
\text { CTD }\end{array}$ \\
\hline \multicolumn{2}{|c|}{ Colon cancer cell line } & \multicolumn{2}{|c|}{ Ovarian cancer cell line } \\
\hline KM12 & 3 & SK-OV-3 & 5 \\
\hline HCT116 & 7 & IGR-OVI & 7 \\
\hline HCT15 & 19 & OVCAR-5 & 10 \\
\hline HТ29 & 7 & OVCAR-4 & 10 \\
\hline SW620 & 11 & OVCAR-3 & 2 \\
\hline HCC-2998 & 14 & OVCAR-8 & 9 \\
\hline \multicolumn{2}{|c|}{ Melanoma cancer cell line } & \multicolumn{2}{|c|}{ Renal cancer cell line } \\
\hline SK-MEL-2 & 3 & TK-10 & 5 \\
\hline LOX-IMVI & 3 & $\mathrm{ACHN}$ & 5 \\
\hline MALME-3M & 13 & RXF393 & 3 \\
\hline M14 & 9 & $\mathrm{SN}-12 \mathrm{C}$ & 7 \\
\hline SK-MEL-5 & 8 & CAKI-1 & 6 \\
\hline UACC-257 & 12 & $786-0$ & 10 \\
\hline SK-MEL-28 & 14 & UO-31 & 14 \\
\hline UACC-62 & 18 & A498 & 20 \\
\hline \multicolumn{2}{|l|}{ CNS cancer cell line } & \multicolumn{2}{|l|}{ Suspension cell line } \\
\hline U251 & 3 & K562 & 3 \\
\hline SNB-19 & 4 & CCRF-CEM & 3 \\
\hline SF-268 & 3 & COLO-205 & 3 \\
\hline SF-295 & 5 & RPMI-8226 & 9 \\
\hline SNB-75 & 3 & MOLT-4 & 6 \\
\hline SF-539 & 10 & & \\
\hline \multicolumn{2}{|l|}{ Lung cancer cell line } & \multicolumn{2}{|c|}{ Breast cancer cell line } \\
\hline EKVX & 8 & BT-549 & 6 \\
\hline NCI-H460 & 6 & MDA-MB-435 & 7 \\
\hline NCI/ADR-RES & 6 & HS-578T & 11 \\
\hline NCI-H226 & 10 & T47-D & 12 \\
\hline A549 & 12 & MDA-MB-231 & 13 \\
\hline HOP92 & 9 & MCF-7 & 29 \\
\hline NCI-H522 & 14 & MDA-MB-468 & 20 \\
\hline NCI-H23 & 16 & \multicolumn{2}{|c|}{ Prostate cancer cell line } \\
\hline NCI-H322M & 8 & PC-3 & 3 \\
\hline HOP62 & 18 & DU-145 & 3 \\
\hline
\end{tabular}

\section{Results}

\section{Cell lines of liver and gastric cancers are highly sensitive to CTD.}

In order to determine whether CTD exhibits any selectivity toward abdominal cancers, we decided to assess and compare the relative sensitivities of 72 cell lines that represent 12 major types of human cancers to the growth inhibitory effect of CTD. Traditionally, such an experiment would involve the use of the NCI60 panel of cell lines that represent the 9 major cancer types of the western society. In this case, however, additional lines representing gastric and liver cancers were also included, because these two types of cancers had been claimed to benefit from treatments with CTD, which was first isolated from Mylabris. The use of the semi-high-throughput IncuCyte system has enabled efficient and accurate assessment of the growth inhibitory effects of CTD on a large number of cell lines. Moreover, the data output has allowed case-by-case examination of the data set and accurate computation of the IC50 value for each tested cell lines. Thus, the IC50s for a total of 72 cell lines representing 12 major types of human cancer were established (Table 1,2). Based on the mean values of the calculated IC50s, it is clear that cell lines from several types of cancers, including those of the prostate cancers, gastric cancers, CCs and hepatoma all have a mean IC50 value below $5 \mu \mathrm{M}$ (Table 3). Of note, although the mean IC50 value for all of the HCC cell lines is not the lowest, a careful examination of the data set reveals that a subset of these cell lines is among those with the lowest IC50 values (Fig. 1, Table 2).

Table 2. CTD IC50 for additional liver cancer cell lines and gastric cancer cell lines.

\begin{tabular}{ll}
\hline & IC50 $(\mu \mathrm{M})$ \\
\hline Gastric cancer cell line & \\
SGC-7901 & 5 \\
MGC-803 & 3 \\
AGS & 3 \\
BGC 823 & 3 \\
Liver cancer cell line & \\
HepG2 & 3 \\
Hep3B & 2 \\
SNU-449 & 5 \\
SNU-387 & 4 \\
Huh7 & 4 \\
LM9 & 6 \\
SMMC7721 & 8 \\
Cholangiocarcinoma cell line & \\
QBC939 & 3 \\
HCCC9810 & 3 \\
RBE & 2 \\
\hline
\end{tabular}

Table 3. CTD Mean IC50 and the range of cell lines for individual types of cancers.

\begin{tabular}{lll}
\hline & Mean & Range \\
\hline Colon cancer cell line & 10 & $3-19$ \\
Melanoma cancer cell line & 10 & $3-18$ \\
Renal cancer cell line & 9 & $3-20$ \\
Prostate cancer cell line & 3 & 3 \\
Ovarian cancer cell line & 7 & $2-10$ \\
Breast cancer cell line & 14 & $6-29$ \\
CNS cancer cell line & 5 & $3-10$ \\
Lung cancer cell line & 11 & $6-18$ \\
Gastric cancer cell line & 4 & $3-5$ \\
Hepatoma cell line & 4 & $2-8$ \\
Cholangiocarcinoma cell line & 3 & $2-3$ \\
Suspension cell line & 5 & $3-9$
\end{tabular}

Clonogenic survival assay was then performed on selected cell lines to further verify the validity of the data obtained using the IncuCyte system. For this experiment, HepG2 and QBC939 were chosen to represent those that were most sensitive to CTD while EKVX the most resistant. The result indicates that HepG2 and QBC939 are indeed highly sensitive to the growth inhibitory effect of CTD, while EKVX remained largely unaffected even at the highest dose examined (Fig. 2). Thus, these data demonstrate that cell lines of different types of human cancers exhibited different sensitivities toward the growth inhibitory 

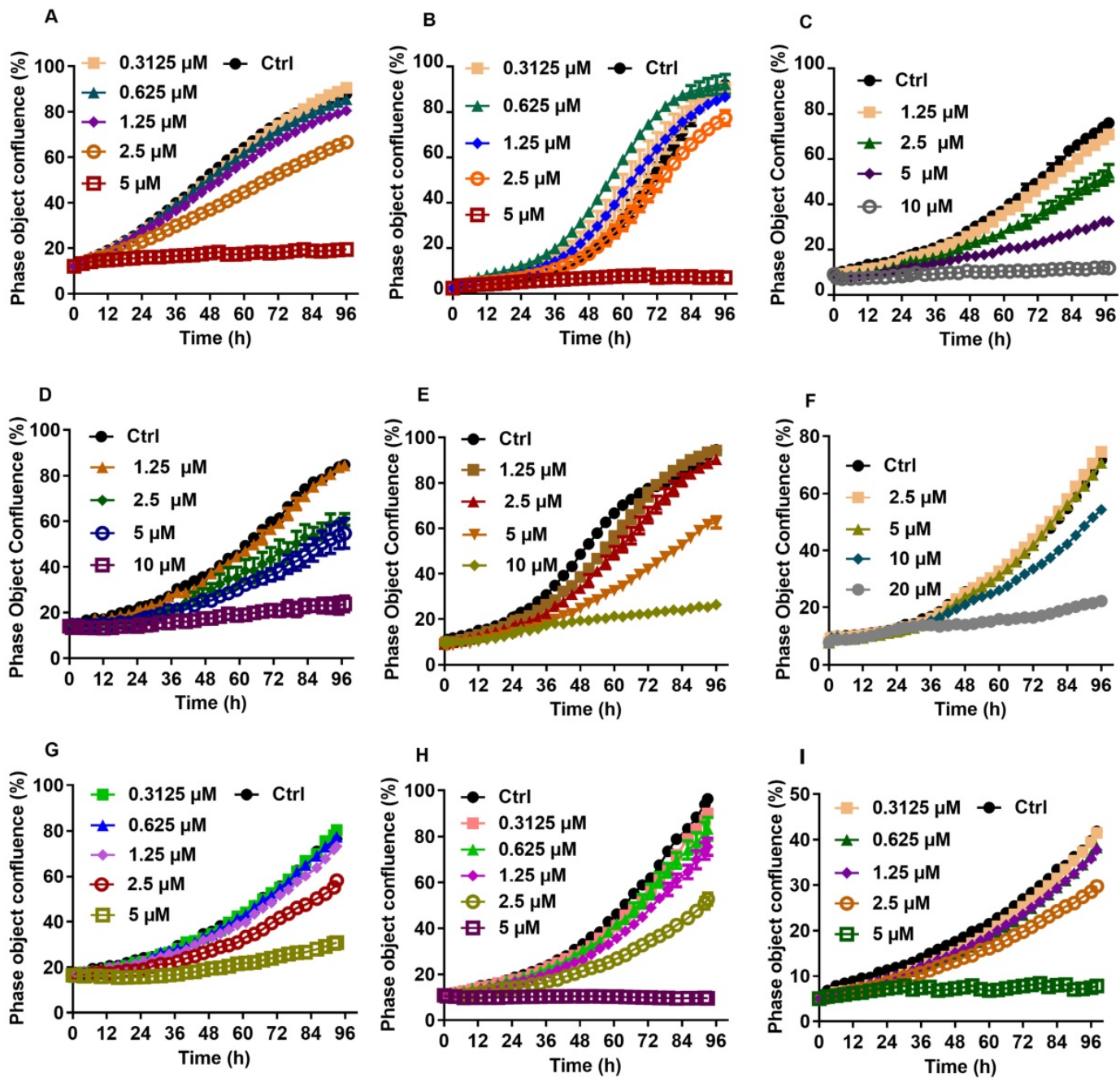

Fig. 1. Growth curves for individual liver cancer cell lines treated with various concentration of CTD. A: HepG2; B: Hep3B; C: Huh7; D: SUN-387; E: SUN-449; G: LM9; F: HCCC9810; H: RBE; I: QBC939. The result showed that cell lines of liver cancer are commonly sensitive to CTD, especially in HepG2 and Hep3B

effect of CTD. In particular, all gastric cancer cell lines and CC cell lines and a subset of HCC cell lines are among the most sensitive ones to the growth inhibitory effect of CTD.

\section{Individual types of cancer cell lines exhibit distinctive trends of sensitivity toward CTD and NCTD.}

When the values of IC90 of CTD and NCTD in each cancer type were compared, it became apparent that for the most past, there is not a tight correlation between the two rankings. For example, for the HCC cell lines, the cells lines with the lowest and the highest rank for CTD and NCTD were Hep3B and SMMC7721; and SNU-449 and Hep3B, respectively (Table 4). A similar discordance between the rankings of IC90 was also observed in other cell lines (Table 5). Thus, there is clearly a discordance in terms of the rankings of sensitivities toward CTD and NCTD among multiple subgroups of cancer cells lines. Such a discordance among multiple subgroups of cancer cell lines between the two compounds, therefore, argues against the notion that the two compounds exert their growth inhibitory effects via similar mechanisms.

\section{CTD and NCTD inhibit growth of HepG2 cells via different mechanisms.}

The clear discordance between the growth inhibitory effects of CTD and NCTD within cell lines of individual cancer types prompted us to examine whether these two drugs might in fact cause their respective growth inhibitory effects through different mechanisms. Growth inhibition can be the result of increased cell death, decreased cell cycle progression, or both. Thus, DNA content-based flow cytometry analysis was used to determine the cell cycle progression and/or cell death of HepG2 cells following the treatments with CTD or NCTD. Indeed, when treated at equally potent growth inhibitory concentrations of CTD (IC50, $3 \mu \mathrm{M}$; IC90, $5 \mu \mathrm{M}$ ) and NCTD (IC50, $18 \mu \mathrm{M}$, IC90, $55 \mu \mathrm{M}$ ), only NCTD, but not CTD caused a significant increase in the sub-G1 fraction, indicative of increased apoptosis; while CTD 
caused a G1 cell cycle arrest (Fig. 3). These data indicate that while a cytostatic effect is the primary cause of growth inhibitory effect of CTD, cytotoxic effect is the main contributing factor for the growth inhibitory effect of NCTD.


Fig. 2. Clonogenic survival data of the three representative cell lines. HepG2 and QBC939 were used to represent those that were most sensitive to CTD while EKVX the most resistant. The result showed that HepG2 and QBC939 were indeed highly sensitive to the growth inhibitory effect of CTD $(P<0.01)$, while EKVX remained resistant to the treatment the highest dose examined. Data are expressed as means $\pm S D$.

Table 4. Different IC50 for CTD and NCTD for individual liver cancer cell lines. --From the lowest to the highest, and side-by-side

\begin{tabular}{lllll}
\hline & IC50 $(\mu \mathrm{M})$ of CTD & (Ranking) & IC50 $(\mu \mathrm{M})$ of NCTD & (Ranking) \\
\hline Hep3B & 2 & $(1)$ & 20 & $(7)$ \\
HepG2 & 3 & $(2)$ & 18 & $(4)$ \\
Huh7 & 4 & $(3)$ & 18 & $(4)$ \\
SNU-387 & 4 & $(3)$ & 18 & $(4)$ \\
SNU-449 & 5 & $(5)$ & 13 & $(1)$ \\
LM9 & 6 & $(6)$ & 17 & $(3)$ \\
SMMC7721 & 8 & $(7)$ & 15 & $(2)$ \\
\hline
\end{tabular}

Table 5. Minimum lethal doses for CTD and NCTD.

\begin{tabular}{lllll}
\hline & $\begin{array}{l}\text { IC90 }(\mu \mathrm{M}) \text { of } \\
\text { CTD }\end{array}$ & $\begin{array}{l}\text { (Ranking) } \\
\text { IC90 }(\mu \mathrm{M}) \text { of } \\
\text { NCTD }\end{array}$ & (Ranking) \\
\hline Colon cancer cell line & & & & \\
KM12 & 5 & $(1)$ & 47 & $(1)$ \\
HCT116 & 12 & $(2)$ & 81 & $(3)$ \\
SW620 & 18 & $(3)$ & 90 & $(4)$ \\
HT29 & 22 & $(4)$ & 53 & $(2)$ \\
HCC-2998 & 27 & $(5)$ & 158 & $(5)$ \\
HCT15 & 36 & $(6)$ & 176 & $(6)$ \\
Melanoma cancer cell line & & & & \\
SK-MEL-2 & 6 & $(1)$ & 16 & $(1)$ \\
LOX-IMVI & 10 & $(2)$ & 79 & $(4)$ \\
MALME-3M & 16 & $(3)$ & 120 & $(7)$ \\
SK-MEL-5 & 22 & $(4)$ & 92 & $(5)$ \\
UACC-62 & 32 & $(5)$ & 73 & $(3)$ \\
UACC-257 & 33 & $(6)$ & 129 & $(8)$ \\
\hline
\end{tabular}

\begin{tabular}{|c|c|c|c|c|}
\hline & $\begin{array}{l}\text { IC90 }(\mu \mathrm{M}) \text { of } \\
\text { CTD }\end{array}$ & (Ranking) & $\begin{array}{l}\text { IC } 90(\mu \mathrm{M}) \text { of } \\
\text { NCTD }\end{array}$ & (Ranking) \\
\hline $\bar{M} 14$ & 35 & (7) & 43 & (2) \\
\hline SK-MEL-28 & 41 & (8) & 92 & (5) \\
\hline \multicolumn{5}{|c|}{ Renal cancer cell line } \\
\hline TK-10 & 8 & (1) & 40 & (4) \\
\hline RXF393 & 11 & (2) & 31 & (2) \\
\hline $\mathrm{ACHN}$ & 15 & (3) & 72 & (6) \\
\hline $\mathrm{SN}-12 \mathrm{C}$ & 17 & (4) & 33 & (3) \\
\hline CAKI-1 & 17 & (4) & 16 & (1) \\
\hline $786-0$ & 18 & (6) & 77 & (7) \\
\hline UO-31 & 34 & (7) & 87 & (8) \\
\hline A498 & 39 & (8) & 63 & (5) \\
\hline \multicolumn{5}{|c|}{ Prostate cancer cell line } \\
\hline PC-3 & 11 & (1) & 13 & (1) \\
\hline DU-145 & 18 & (2) & 63 & (2) \\
\hline \multicolumn{5}{|c|}{ Ovarian cancer cell line } \\
\hline OVCAR-3 & 4 & (1) & 64 & (2) \\
\hline SK-OV-3 & 13 & (2) & 53 & (1) \\
\hline IGR-OVI & 13 & (2) & 65 & (4) \\
\hline OVCAR-4 & 21 & (4) & 64 & (2) \\
\hline OVCAR-5 & 24 & (5) & 82 & (5) \\
\hline OVCAR-8 & 31 & (6) & 114 & (6) \\
\hline \multicolumn{5}{|c|}{ Breast cancer cell line } \\
\hline MDA-MB-435 & 17 & (1) & 54 & (3) \\
\hline BT-549 & 19 & (2) & 19 & (1) \\
\hline HS-578T & 31 & (3) & 48 & (2) \\
\hline MDA-MB-231 & 35 & (4) & 55 & (4) \\
\hline T47-D & 37 & (5) & 127 & (6) \\
\hline MDA-MB-468 & 123 & (6) & 70 & (5) \\
\hline MCF-7 & 147 & (7) & 136 & (7) \\
\hline \multicolumn{5}{|c|}{ CNS cancer cell line } \\
\hline U251 & 7 & (1) & 34 & (2) \\
\hline SNB-75 & 7 & (1) & 45 & (5) \\
\hline SNB-19 & 9 & (3) & 40 & (3) \\
\hline SF-268 & 16 & (5) & 30 & (1) \\
\hline SF-295 & 34 & (6) & 73 & (6) \\
\hline SF-539 & 38 & (7) & 40 & (3) \\
\hline \multicolumn{5}{|c|}{ Lung cancer cell line } \\
\hline EKVX & 12 & (1) & 45 & (1) \\
\hline NCI-H322M & 16 & (2) & 48 & (2) \\
\hline NCI-H460 & 17 & (3) & 56 & (4) \\
\hline NCI/ADR-RES & 21 & (4) & 48 & (3) \\
\hline A549 & 25 & (5) & 86 & (7) \\
\hline HOP92 & 30 & (6) & 82 & (6) \\
\hline NCI-H23 & 35 & (7) & 177 & (10) \\
\hline HOP62 & 35 & (7) & 106 & (9) \\
\hline NCI-H522 & 36 & (9) & 90 & (8) \\
\hline NCI-H226 & 40 & (10) & 63 & (5) \\
\hline \multicolumn{5}{|c|}{ Suspension cell line } \\
\hline COLO-205 & 4 & (1) & 44 & (5) \\
\hline K562 & 8 & (2) & 39 & (4) \\
\hline CCRF-CEM & 12 & (3) & 29 & (3) \\
\hline MOLT-4 & 16 & (4) & 12 & (1) \\
\hline RPMI-8226 & 47 & (5) & 17 & (2) \\
\hline \multicolumn{5}{|c|}{ Gastric cancer cell line } \\
\hline MGC-803 & 8 & (1) & 74 & (4) \\
\hline AGS & 8 & (1) & 34 & (2) \\
\hline SGC-7901 & 10 & (3) & 29 & (1) \\
\hline BGC 823 & 16 & (4) & 36 & (3) \\
\hline \multicolumn{5}{|c|}{ Hepatoma cell line } \\
\hline HepG2 & 5 & (1) & 55 & (7) \\
\hline Нер3В & 7 & (2) & 44 & (5) \\
\hline Huh7 & 8 & (3) & 43 & (3) \\
\hline LM9 & 12 & (4) & 49 & (6) \\
\hline SNU-449 & 12 & (4) & 35 & (1) \\
\hline SNU-387 & 13 & (6) & 39 & (2) \\
\hline SMMC7721 & 13 & (6) & 43 & (3) \\
\hline \multicolumn{5}{|c|}{$\begin{array}{l}\text { Cholangiocarcinoma cell } \\
\text { line }\end{array}$} \\
\hline RBE & 6 & (1) & 58 & (2) \\
\hline QBC939 & 9 & (2) & 53 & (1) \\
\hline НССС 9810 & 9 & (2) & 65 & (3) \\
\hline
\end{tabular}



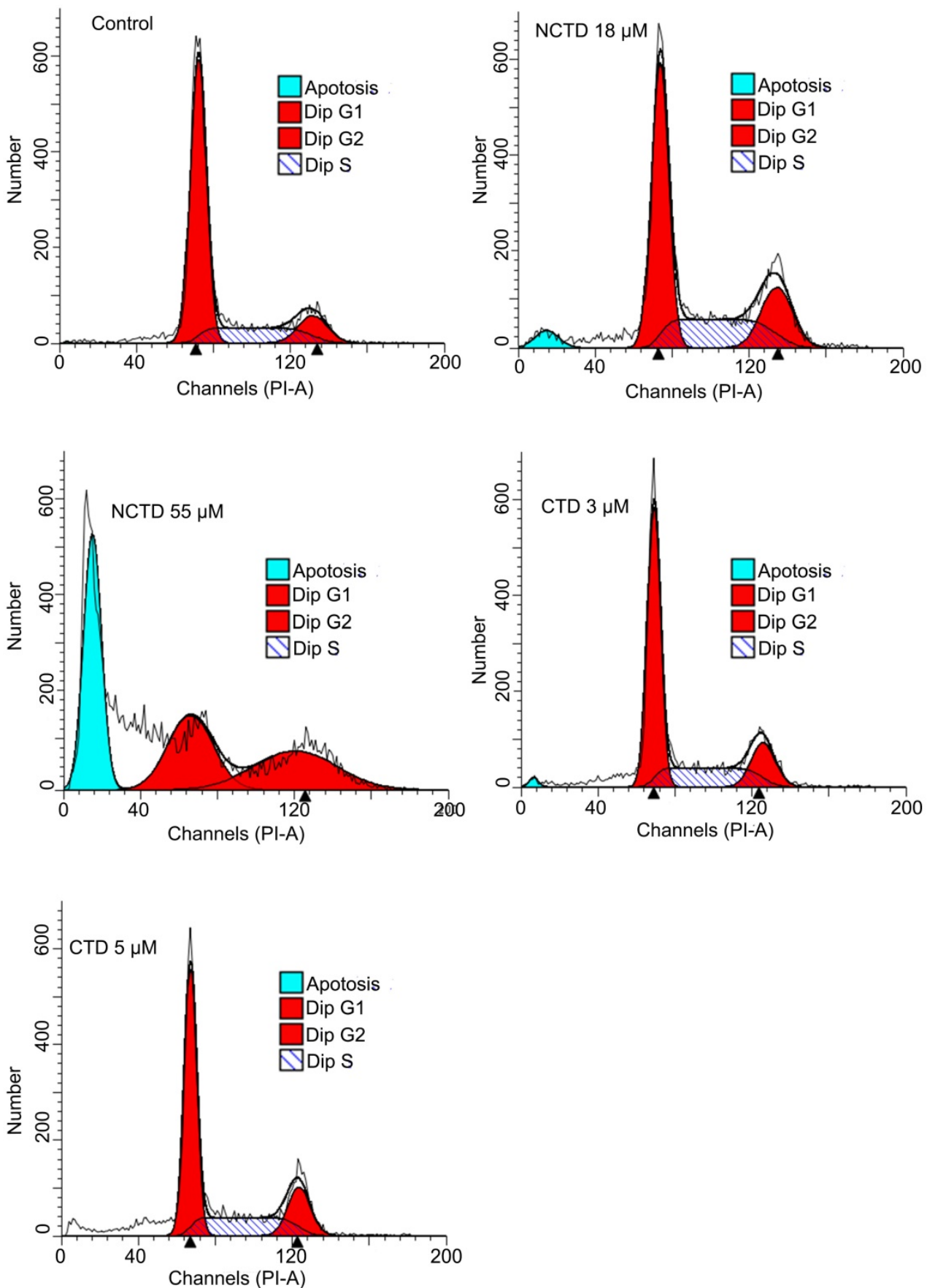

Fig. 3. DNA content-based flow data: Distinctive responses of HepG2 toward CTD and NCTD. when treated at equal potent growth inhibitory concentrations of CTD (IC50, $3 \mu \mathrm{M}$; IC90, $5 \mu \mathrm{M}$ ) and NCTD (IC50, $18 \mu \mathrm{M}$, IC90, $55 \mu \mathrm{M}$ ), only NCTD, caused a significant increase in the sub-G1 fraction, indicative of apoptosis; while CTD apparently caused a Gl cell cycle arrest.

\section{Discussion}

Despite the long-standing claim that CTD and/or NCTD have clinical indication for other abdominal cancers, in particular liver cancers, a systemic comparison among the various types of human cancer cell lines have not been performed. One possible reason for the lack of such comparison is that the gold-standard cell panel that is usually used for such an experiment, the NCI60 panel, does not include cell lines of liver cancers and gastric cancers ${ }^{[20]}$. The experimental data presented here indicate that a significant fraction of cell lines derived from liver cancers including HCCs and CCs, are among the most sensitive cell lines toward the growth inhibitory effect of CTD, lending support for the ancient claim that CTD and Mylabris were effective anticancer agents for liver cancers ${ }^{[5]}$. Interestingly, other types of GI cancers, including gastric and colon cancers, do not appear to be particularly more 
sensitive to CTD. Thus, despite the fact that CTD is a potent poison, it remains feasible to achieve therapeutic anti-cancer benefit for liver cancers with the tolerable doses of CTD. Accordingly, additional effort in finding the more effective use of CTD and its derivatives for anti-liver cancer treatment is warranted.

Intriguingly, however, we found that there existed a wide spread discordance regarding the growth inhibitory potency between CTD and NCTD toward individual subgroups of cancer cell lines. This finding is in stark contrast to the current assumption that CTD and NCTD exerts its anti-cancer effect via similar mechanism(s) ${ }^{[4]}$. Rather, it has raised the possibility that these two compounds likely exert their growth inhibitory effects and hence anti-tumor effects through different mechanisms, perhaps by acting upon distinct sets of molecular targets ${ }^{[9-11]}$. Indeed, we showed here that CTD and NCTD caused the growth inhibitory effect of HepG2 cells with different mechanisms. Interestingly, more recent structurefunction studies have revealed that the two methyl group that are present in CTD but not in NCTD play an important role in enhancing the binding affinity toward PP2A ${ }^{[19]}$. It follows, therefore, that NCTD, a demethylated derivative of CTD, might have different target specificities than CTD. This then raised the possibility that in vivo, CTD and NCTD may also exert their antitumor effects through different mechanisms.

Taken together, the new information presented in this report have called into question the notion that NCTD is a true functional derivative of CTD, the original entity that had been claimed to have potent antitumor effect against abdominal tumors, particularly liver cancers. Accordingly, it will be important to clearly separate these two entities in terms of their antitumor effect as well as mechanisms in order to make better use of these agents and their derivatives for anticancer treatments.

Over all, the data presented here lend further support to the ancient claim that Mylabrsis had unique indication for abdominal masses, particularly liver cancers. Thus, CTD-based regimen(s) remain a promising option for liver cancers including perhaps both HCCs and CCs. However, it is imperative to clearly separate CTD and NCTD. Specifically, although NCTD remains a promising lead for developing effective antitumor agent, it is not a good representative of CTD. Furthermore, for liver cancers, the focus should be on CTD, not its demethylated derivative NCTD and the derivatives thereof. Accordingly, targeted inhibition of PP2A in the liver or within the liver cancer microenvironment should be a main objective.

\section{Abbreviations}

CTD: cantharidin; NCTD: norcantharidin; IC50s: half maximal inhibitory concentrations; IC90s: 90\% inhibitory doses; MTDs: maximal tolerable doses; HCCs: hepatocellular carcinomas; CCs: cholangiocarcinoma; MTD: Maximal tolerable dose; PP2A: protein phosphatases $2 \mathrm{~A}$.

\section{Acknowledgments}

This study was supported by a fund from Beijing University of Chinese Medicine.

\section{Competing Interests}

The authors have declared that no competing interest exists.

\section{References}

1. Regorafenib Approved for Liver Cancer. Cancer Discov. 2017; 7: 660.

2. Lang L. FDA approves sorafenib for patients with inoperable liver cancer. Gastroenterology. 2008; 134: 379.

3. Li J, Wang L, Cong N, Shi C, Bu W, Song J, et al. Efficacy of Sorafenib for Advanced Hepatocellular Carcinoma and Prognostic Factors. Hepatogastroenterology. 2014; 61: 954-7.

4. Wang GS. Medical uses of mylabris in ancient China and recent studies. J Ethnopharmacol. 1989; 26: 147-62.

5. Zhang W, Ma YZ, Song L, Wang CH, Qi TG, Shao GR. Effect of cantharidins in chemotherapy for hepatoma: a retrospective cohort study. Am J Chin Med. 2014; 42: 561-7.

6. Chen AW, Tseng YS, Lin CC, Hsi YT, Lo YS, Chuang YC, et al. Norcantharidin induce apoptosis in human nasopharyngeal carcinoma through caspase and mitochondrial pathway. Environ Toxicol. 2017.

7. Ye K, Wei Q, Gong Z, Huang Y, Liu H, Li Y, et al. Effect of norcantharidin on the proliferation, apoptosis, and cell cycle of human mesangial cells. Ren Fail. 2017; 39: 458-64.

8. Deng L, Tang S. Norcantharidin analogues: a patent review (2006 - 2010). Expert Opin Ther Pat. 2011; 21: 1743-53.

9. Liu XH, Blazsek I, Comisso M, Legras S, Marion S, Quittet P, et al. Effects of norcantharidin, a protein phosphatase type-2A inhibitor, on the growth of normal and malignant haemopoietic cells. Eur J Cancer. 1995; 31A: 953-63.

10. Ogris E, Gibson DM, Pallas DC. Protein phosphatase 2A subunit assembly: the catalytic subunit carboxy terminus is important for binding cellular B subunit but not polyomavirus middle tumor antigen. Oncogene. 1997; 15: 911-7.

11. Tolstykh T, Lee J, Vafai S, Stock JB. Carboxyl methylation regulates phosphoprotein phosphatase $2 \mathrm{~A}$ by controlling the association of regulatory B subunits. EMBO J. 2000; 19: 5682-91.

12. Wu J, Tolstykh T, Lee J, Boyd K, Stock JB, Broach JR. Carboxyl methylation of the phosphoprotein phosphatase 2A catalytic subunit promotes its functional association with regulatory subunits in vivo. EMBO J. 2000; 19: 5672-81.

13. Yu XX, Du X, Moreno CS, Green RE, Ogris E, Feng Q, et al. Methylation of the protein phosphatase $2 \mathrm{~A}$ catalytic subunit is essential for association of Balpha regulatory subunit but not SG2NA, striatin, or polyomavirus middle tumor antigen. Mol Biol Cell. 2001; 12: 185-99.

14. Wei H, Ashby DG, Moreno CS, Ogris E, Yeong FM, Corbett AH, et al. Carboxymethylation of the PP2A catalytic subunit in Saccharomyces cerevisiae is required for efficient interaction with the B-type subunits Cdc55p and Rts1p. J Biol Chem. 2001; 276: 1570-7.

15. Puerto Galvis CE, Vargas Mendez LY, Kouznetsov VV. Cantharidin-based small molecules as potential therapeutic agents. Chem Biol Drug Des. 2013; 82: 477-99.

16. Hill TA, Stewart SG, Gordon CP, Ackland SP, Gilbert J, Sauer B, et al. Norcantharidin analogues: synthesis, anticancer activity and protein phosphatase 1 and 2A inhibition. ChemMedChem. 2008; 3: 1878-92.

17. Deng L, Dong J, Wang W. Exploiting protein phosphatase inhibitors based on cantharidin analogues for cancer drug discovery. Mini Rev Med Chem. 2013; 13: 1166-76.

18. Tian X, Zeng G, Li X, Wu Z, Wang L. Cantharidin inhibits cell proliferation and promotes apoptosis in tongue squamous cell 
carcinoma through suppression of miR-214 and regulation of p53 and Bcl-2/Bax. Oncol Rep. 2015; 33: 3061-8.

19. Hill TA, Stewart SG, Sauer B, Gilbert J, Ackland SP, Sakoff JA, et al. Heterocyclic substituted cantharidin and norcantharidin analogues--synthesis, protein phosphatase (1 and $2 \mathrm{~A})$ inhibition, and anti-cancer activity. Bioorg Med Chem Lett. 2007; 17: 3392-7.

20. Shoemaker RH. The NCI60 human tumour cell line anticancer drug screen. Nat Rev Cancer. 2006; 6: 813-23. 